\title{
Academic Stress, Anxiety and Depression among the Students of Armed Forces Medical College, Dhaka Cantonment
}

\author{
Hossain $\mathrm{MM}^{1}$, Wahab $\mathrm{MA}^{2}$
}

\begin{abstract}
Introduction: Study in Medical College can act as a contributing factor in developing depression in medical students which may have possible negative academic and professional consequences. Study in any medical course is perceived as being inherently stressful across the globe. Studies on psychological problems such as academic stress, anxiety and depression among medical students have seen that these disorders are under diagnosed and under treated. In this background the present study was carried out with an aim to assess the magnitude of depression and its associated factors in medical students in AFMC.
\end{abstract}

Objective: To find out the prevalence of depressive symptoms and its associated factors among the students of Armed Forces Medical College (AFMC), Dhaka, Bangladesh.

Materials and Methods: This descriptive type of cross sectional study was carried out in AFMC, Dhaka, Bangladesh for a period from February to April 2014. A total of 211 students studying from 1styear to 4th year MBBS participated in the study. Depression was assessed by Goldberg's General Health Questionnaire (GHQ-28) and Beck Depression Inventory(BDI) scoring was used to find out the level of depression. BDI scoring 0-10 was considered as normal ups and downs, 11-20 as mild depression, 21-30 as moderate depression, 31-40 as severe depression and more than 40 as extreme depression. Additional questions regarding socio demographic variables were also included. Data analysis was done by software SPSS 19 for windows.

Results: A total of 211 students participated in the study. Among them 86(40.8\%) students were reported as having mild to moderate depressive symptoms. Depression was very significantly $(p<0.001)$ higher in 1 st year $55(83.3 \%)$ than 2 nd year $25(38.46 \%)$, 3rd year $03(5.45 \%)$ and 4 th year $03(12 \%)$ students.
Depression was significantly $(p<0.05)$ higher in Non English Medium background $82(38.8 \%)$ than English Medium background 04(1.9\%).

Conclusion: Depression may be a significant hidden problem for few of the Medical students and mechanisms to identify and help students with mental health problems should be seriously considered. This calls for in-house counseling service and mentorship program at medical colleges for early detection and treatment of these problems that may help in the improvement of academic performance.

\section{Introduction}

According to $\mathrm{WHO}$, depression is a highly common mental state and by 2020 it would be the second-most prevalent condition worldwide ${ }^{1}$. There is considerable evidence that rates of academic stress, anxiety and depression are higher in medical students and that these rates continue to remain elevated when these students become physician ${ }^{2}$. Medical students are a valuable human resource for our future and depression in them leads to learning difficulties which may negatively affects the patients care. Studies from other parts of the world have shown a high prevalence of depression in them leading to learning difficulties which may negatively affects the patient care ${ }^{3}$. There are no such studies in our country ${ }^{4}$. The present study was carried out to determine the prevalence of depression in the MBBS students in AFMC.

In any medical course students have to face lots of course content and have to articulate that information into practical life which involves most of the times in study. So medical students have to encounter academic pressure as well as to adjust the new environment of the medical college specially in preclinical years. So they have less opportunity to

1. Maj Molla Muntasir Hossain, MBBS, MPH (HSM \& P), CCD, GSO-2 (Training), AFMC, Dhaka 2. Lt Col Md Abdul Wahab, MBBS, MD (Biochemistry), Commanding Officer, Border Guard Hospital, Guimara, Khagrachari. 
relax and as a consequence may suffer from serious sleep deprivation, impaired judgment, reduced concentration, loss of self-esteem, along with anxiety and depression which affects their learning ability and academic performance. Studies on psychological problems such as academic stress, anxiety and depression among medical students have found that these disorders are under diagnosed and under treated $^{5}$. Therefore it becomes imperative to study the overall mental health status and particularly prevalence of depression among medical students as these constitute neglected public health problems. It is very important to prevent the ill effects of depression on one's academic attainment and career through early identification and effective intervention measures ${ }^{6}$. In this background the present study was undertaken with an aim to assess the magnitude of depression and to describe the factors influencing depression among the students in Armed Forces Medical College (AFMC), Dhaka, Bangladesh.

\section{Materials and Methods}

This descriptive type of cross sectional study was conducted from February to April 2014 in AFMC, Dhaka, Bangladesh. A total of 211 respondents from 1 st year to 4 th year MBBS had participated in this study. 5th year students were excluded because of unwillingness. Participation in the study was on voluntary basis and informed written consent was taken from all the respondents and permission for study was taken from the appropriate authority of AFMC. The respondents were given full assurance that they may or may not answer the question and also assured that the findings of the study will not be disclosed to the authority and will have no negative impact in their personal life. Students identified with clinically significant depression were offered counseling or appropriate help. The first section of the questionnaire focused on socio demographic particulars including age, sex, year of study, use of any medicine for depression and medium of teaching in premedical education.

All the respondents were interviewed by using Goldberg's General Health Questionnaire (GHQ-28) which is developed by David Goldberg at Institute of Psychiatry, London as a screening instrument in the community $^{7}$. Grade and level of depression was measured by using Beck Depression Inventory (BDI) scale. There were total twenty one questions each having 0 to 3 score. So the highest possible total score for the whole test would be 63 . BDI scoring 0-10 considered as normal ups and downs, 11-20 as mild depression, 21-30 as moderate depression, $31-40$ as severe depression and more than 40 as extreme depression $^{8}$.

The data were analyzed by using software SPSS 19 for windows. Data were expressed as mean or percentages as appropriate. Chi-square test was done to find out the association between status of depression and various factors under study.

\section{Results}

A total of 211 students returned the fully answered questionnaire. Mean age of the students were 20.83 years (SD \pm 0.01247 ). About $86(40.8 \%$ ) students had symptoms suggestive of depression (Fig-I). Among the depressed mild depression was found in $68(79 \%)$ and moderate depression was found in $18(21 \%)$ students (Table-I), but no case of severe and extreme depression was found in this study. Male respondents were $82(38.8 \%)$ and Female were $129(61.2 \%)$. In that $39(47.6 \%)$ of the male and $47(36.4 \%)$ of female students were in various grade of depression, but this difference was not statistically significant (Table-II). Depression was very significantly $(p<0.001)$ higher in 1 st year students $55(83.3 \%$ ) than 2 nd year $25(38.5 \%)$, 3rd year $03(5.5 \%)$ and 4 th year $03(12 \%)$ students (Table-III). Among the depressed 30(34.9\%) students were under medication. About the medium of teaching in premedical education; among the total respondents 41(19.4\%) were from English Medium/ Version and $170(80.6 \%)$ were from non-English Medium/ version. Depression was significantly $(p<0.05)$ higher in non-English medium students $82(38.8 \%)$ than English Medium 04(1.9\%)(Table-IV).

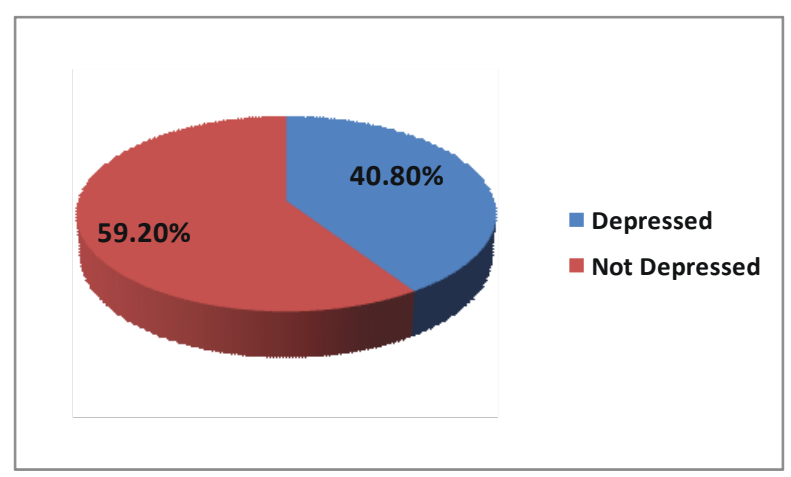

Fig-I: Depression state and Grade of depression among students $(n=211)$. 
Table-I: Distribution of depressed students according to Grade of Depression ( $n=86$ )

\begin{tabular}{|l|c|c|}
\hline Grade & Number & Percentage \\
\hline Mild & 68 & $79 \%$ \\
\hline Moderate & 18 & $21 \%$ \\
\hline
\end{tabular}

Table-II: Distribution of respondents according to Sex $(n=211)$

\begin{tabular}{|c|c|c|c|}
\hline \multirow{3}{*}{ Sex } & \multicolumn{2}{|c|}{ State of Depression } & \multirow{2}{*}{ Total } \\
\hline & Not depressed & Depressed & \\
\hline & $\mathrm{n}(\%)$ & $\mathrm{n}(\%)$ & $n(\%)$ \\
\hline Male & $43(52.40)$ & $39(47.60)$ & $82(38.80)$ \\
\hline Female & $82(63.57 \%)$ & $47(36.43)$ & 129(61.20) \\
\hline Total & 125 & 86 & 211(100) \\
\hline
\end{tabular}

Table-III: Distribution of respondents according to Year of MBBS Course $(n=211)$.

\begin{tabular}{c|r|r|c|}
\hline Year & Depressed & Not Depressed & Total \\
\hline $1^{\text {st }}$ year & $55(83.3 \%)$ & $11(16.7 \%)$ & 66 \\
\hline $2^{\text {nd }}$ year & $25(38.46 \%)$ & $40(61.54 \%)$ & 65 \\
\hline $3^{\text {rd }}$ year & $3(05.45 \%)$ & $52(94.55 \%)$ & 55 \\
\hline $4^{\text {th }}$ year & $3(12.0 \%)$ & $22(88 \%)$ & 25 \\
\hline Total & 86 & 125 & 211 \\
\hline
\end{tabular}

Table-IV: Distribution of respondents on the basis of Medium of teaching in Premedical Education $(n=211)$

\begin{tabular}{l|r|r|r|}
\hline \multirow{2}{*}{ Medium of Education } & Not Depressed & Depressed & Total \\
\cline { 2 - 3 } & $\mathrm{n}(\%)$ & $\mathrm{n}(\%)$ & \\
\hline $\begin{array}{l}\text { English Medium/ English } \\
\text { version students }\end{array}$ & $37(17.5 \%)$ & $04(1.9 \%)$ & $41(19.4 \%)$ \\
\hline $\begin{array}{l}\text { Bangla \& other Medium } \\
\text { students }\end{array}$ & $88(41 \cdot 7 \%)$ & $82(38 \cdot 8 \%)$ & $170(80.6 \%)$ \\
\hline Total & $125(59.2)$ & $86(40.8)$ & 211 \\
\hline
\end{tabular}

\section{Discussion}

Medical college is recognized as a stressful environment that often exerts a negative effect on the academic performance, physical health and psychological wellbeing of the students. The personal and social sacrifice that the students have to make in order to maintain good academic results in a highly competitive environment put them under a lot of stress which may end up in wide spectrum of psychological disorders like academic stress, anxiety, depression etc ${ }^{9}$. In this study symptoms suggestive of mild to moderate depression were found in $40.8 \%$ of medical students which corresponds with prevalence rates found in other developing countries ${ }^{10,11}$. This study finding agrees with the findings of a study in a private sector medical college in Mumbai, India where depression was present in $39.9 \%$ students $^{12}$ and also consistent with study findings of MS sherina et $\mathrm{al}^{13}$ from Malaysia where the prevalence of depression was $33.6 \%$.
Similar type of study conducted in Pakistan by Shaikh BT et al $^{14}$ among Pakistan Medical students where depression was found in $60 \%-70 \%$ of the students and Ganesh Kumar et al $^{15}$ reported the prevalence of depression among medical students in Southern India, to be as high as $71.25 \%$ which were not consistent with this study. This wide range in the magnitude of depression in both the studies of Pakistan and Southern India can be attributed to variations in the types of scales used in the screening and different socio demographic, geographic backgrounds of students under study. Again study conducted by Thomas $\mathrm{H}$ et al $^{16}$ among medical students of University of Mississippi school of Medicine, United States and Marie Dahlinet al $^{17}$ at Sweden, where prevalence was $23 \%$ and $12 \%$ respectively. This might be due to having sufficient exposure of medical contents in their premedical schools.

In this study male students having more symptoms of depression as compared to female students which are not consistent with reports from US and Canadian Medical Student in a study by Dr. Liselotte N, Dyrbye in Mayo clinic, Minnesota, USA ${ }^{18}$. In this study we found language barrier is related with depression. In this study prevalence of depressive symptoms was high among newly entered (1st year) students as compared to the senior students which are consistent with similar studies $^{19-22}$. This could be due to language barrier, stress of new study environment and greater degree of work load with obligations to succeed, home sickness as most of them might live far from home for the first time, change in their sleeping and eating habits and lack of leisure time. On the other hand symptoms were less in senior medical students may be due to gradual adaptation to the environment and the study course. In our study we found language barrier is related with depression. This problem can be overcome by making change in the premedical curriculum as well as introduction of English foundation course at the beginning of MBBS course. Self-medication by students concurrent with depression is a matter of grave concern. Preventive education and introduction of counseling programs in medical curriculum can overcome the situation.

\section{Conclusion}

In this study we found $83.3 \%$ of 1 st year students having mild to moderate depression which is an alarming situation. It has been stated that young doctors should be given the same care and support that we expect them 
to provide to their patients. The same should be extended to medical students in order to promote resilience and personal fulfillment and for enhancement of professionalism and patient care. These calls for in house counseling services and mentorship program at medical colleges for early detection and treatment of these problems so that future doctors can concentrate on their studies and become a better doctor. Therefore, an effective system for the prediction of the development of depression in medical students needs to be developed and interventions aimed at reducing the incidence of depression needs further research.

\section{References}

1. World Health Organization. Mental and neurological disorders. Fact sheet No 265, December 2001. Indian J Med Sci 2002 January; 56(1):25-9.

2. Levine RE, Bryant SG. The depressed physician: A different kind of impairment. Hosp Physician 2000; 36:67-73.

3. Abdulghani HM, AlKanhal AA, Mahmoud ES et al. Stress and its effects on medical students: A cross-sectional study at a college of medicine in Saudi Arabia. J Health Popul Nutr 2011 Oct; 29(5):516-22.

4. Lasaa L, Ayuso-Mateos JL, Vazquez-Barqueroa JL et al. The use of the Beck Depression Inventory to screen for depression in the general population: A preliminary analysis. Journal of Affective Disorders 2006; 57(1-3):261-5.

5. Levine RE, Breitkopf CR, Sierles FS et al. Complications Associated With Surveying Medical Student Depression: The Importance of Anonymity. Academic Psychiatry 2003; 27:12-8.

6. Supe AN. A study of stress in medical students at Seth GS Medical College. J Postgrad Med 1998; 44:1-6.

7. Goldberg DP. The General Health Questionnaire (GHQ). Companion to Psychiatric studies1972; 172-3.

8. Beck AT, Ward $\mathrm{CH}$, Mendelson $\mathrm{M}$ et al. An inventory for measuring depression. Arch Gen Psych 1961; 4:53-63.

9. Rosvold EO, Bjertness E. Physicians who do not take sick leave: Hazardous heroes? Scand J Public Health 2001; 29:71-5.

10. Rael D Strous, Shoenfeld N, Lehman A et al. Medical students self-report of mental health conditions. International Journal of Medical Education 2012; 3:1-5.
11. Assadi SM, Nakhaei MR, Najafi F et al. Mental health in three generations of Iranian medical students and doctors: A cross-sectional study. Social Psychiatry and Psychiatric Epidemiology 2007; 42:57.

12. Singh A, Lal A, Shekhar. Prevalanceof Depression among Medical Students of a Private Medical College in India. Online J Health Allied Scs 2010; 9(4):8

13. Sherina MS, Med M, Rampal L et al. Psychological Stress among Undergraduate Medical Students. Med J Malaysia 2004; 59:207-11.

14. Shaikh BT, Kahloon A, Kazmi M et al. Students, stress and coping strategies: A case of Pakistani medical school. Educ Health (Abingdon) 2004; 17:346-53.

15. Ganesh SK, Jain A, Supriya H. Prevalence of depression and its associated factors using Beck's Depression Inventory among students of a medical college in Karnataka. Indian Journal of Psychiatry 2012; 54(3):223-6.

16. Mosley TH, Perrin SG, Neral SM et al. Stress, coping and Well-being among Third year Medical Students. Academic Medicine 1994; 69:765-7.

17. Dahlin M, Joneborg N, Runeson B. Stress and depression among medical students: A cross-sectional study. Medical Education 2005; 39:594-604.

18. Liselotte N, Dyrbye MD, Matthew RT et al. Systematic Review of Depression, Anxiety, and other Indicators of Psychological Distress among US and Canadian Medical Students. Academic Medicine 2006; 81:354-73.

19. Roh MS, Jeon HJ, Kim H et al. The prevalence and impact of depression among medical students: A Nationwide CrossSectional Study in South Korea. Acad Med 2010 August; 85(8):1384-90

20. Dyrbye LN, Thomas MR, Shanafelt TD. Systematic review of depression, anxiety and other indicators of psychological distress among USA and Canadian medical students. Acad Med 2006; 81:354-73.

21. Dr Shah Navas P. Stress among Medical Students. Kerala Medical Journal, April-June 2012; 5(2):34-37. available at http://journals.publishmed.com/index.php/KMJ/article/viewFile/ $303 / 320$.

22. Inam SNB, Saqib A, Alam E. Prevalence of anxiety and depression among medical students of private university. $\mathrm{J}$ Pak Med Assoc 2003; 53:44-7. 